\title{
Governance and Auditing the Implementation of the Sustainable Development Goals (SDGs): Challenges of the Preparedness Phase
}

\author{
Saleh Ali Alagla ${ }^{1}$ \\ ${ }^{1}$ Department of Accounting, Umm Al-Qura University, Saudi Arabia \\ Correspondence: Saleh Ali Alagla, Department of Accounting, Umm Al-Qura University, Saudi Arabia.
}

Received: February 27, 2019

Accepted: March 20, 2019

Online Published: March 21, 2019

doi:10.5539/ibr.v12n4p98

URL: https://doi.org/10.5539/ibr.v12n4p98

\begin{abstract}
This paper aims to perform an in-depth analysis of the Sustainable Development Goals (SDGs) which have been implemented by the United Nations in the year 2015. The research is based on performing an audit of the design and structured framework in order to understand the level of its successful implementation along with highlighting the grey areas and potential threats which require a proactive and strategic move. All the presentations and discussions which happened in the 15th General Auditing Bureau (GAB) Annual Seminar, being held in Saudi Arabia in the year 2018, have been assessed and evaluated to draw a conclusion.

This study has adopted an exploratory paradigm which is termed as interpretivism followed by qualitative research and analysis approach where secondary data set has been used. The main sources of data were the deliberations and discussions of the GAB seminar along with relevant information sources concerning SDGs such as the UN reports and recommendations of other conferences coupled with symposia on the subject. There are certain limitations of the study which include limited availability of literature which weakens the theoretical foundation of the subject of the present research. The analysis of the data set has revealed the presence of institutional and professional preparedness intending the smooth implementation of SDGs. However, analysis of the discussion on the seminar has highlighted specific gaps which might challenge the efficacy of the program and hence requires a necessary action.
\end{abstract}

Keywords: sustainable development goals, governance, The $15^{\mathrm{TH}}$ GAB Seminar, The UN 2030 Agenda, auditing

Paper Type: Research Study

\section{Introduction}

In the last ten years, the domain of sustainability has been extensively researched (Laszlo \& Zhexembayeva, 2017). The literary analysis has highlighted that sustainability affects all the aspects of human life and is much concerned with human activities (Clayton \& Radcliffe, 2015). It spans from maintaining a change in the eco-system, through the exploitation of resources and evaluation and selection of alternative investment options to directing technological research and development and embrace the change in order to meet current and future needs and human preferences (Crane \& Matten, 2016). In the past decade, lots of sustainability-related efforts have been made at both individual and institutional level. The formulation and structuring of Sustainable Development Goals (SDGs), also known as "the Global Goals" is one of the best and practical examples of such efforts accredited to the United Nations.

Based on the success of UN's Millennium Development Goals (MDGs), the core focus of SDGs has been directed towards the eradication of poverty, protection of planet and promotion of peace and prosperity among the people. These SDGs (17 in total) are interlinked; given that the achievement of one SDG fosters the increased chances of availing one or more SDGs. In its real sense, SDGs came into effect in January 2016 and now is a major influencer of United Nation's Development Program (UNDP) which encompasses a considerable growth and development potential (at least until 2030) in different areas. Achieving these SDGs requires real contributions from the stakeholders including Government, the private sector, civil society, and individuals. UNDP is working in around 170 countries and territories for the achievement of these SDGs.

Since the concept of sustainable development goals has been introduced around thirty-years ago (United Nations World Commission on Environment and Development, 1987), these goals are considered as the most noticeable 
hub of departure for leveraging many dimensions of environmental and human development ambitions. The issue is still alive and dynamic so that General Assembly at the United Nation's has included it in its meeting agenda - being held in 2017 - as one of the core discussion points.

Over the years, sustainable development goals (SDGs) attracted the attention of researchers (Biermann et al., 2017; Hak et al., 2015; Holden et al., 2017). The role of accounting in advancing sustainable development in the countries is a vital SDG theme that emerged over time (Guthrie et al., 2010). However, there is little research that investigates issues related to auditing and monitoring of the implementation of SDGs in its new format. In the last three decades, considerable efforts have been made in the area of development of supreme audit institutions (SAIs) so that SDGs and their implementation can be harmonized (Reichborn-Kjennerud \& Johnsen, 2018). One such effort is the development of an international body which is called the International Organization of Supreme Audit Institutions (INTOSAI). The said institution provided an institutional framework for supreme audit institution "to promote development and transfer of knowledge, improve government auditing worldwide and enhance professional capacities, standing and influence of member SAIs in their respective countries" (INTOSAI, 2019). For achieving specific goals, INTOSAI works in coordination with the United Nations and member countries' SAIs.

In Saudi Arabia, the General Auditing Bureau (GAB) is the representative of the Kingdom in the INTOSAI. GAB organizes seminars and workshops with a view to exchange knowledge and experience and to harmonize the auditing process. One such event is the $15^{\text {th }} \mathrm{GAB}$ Annual Seminar named as "Auditing the Implementation of Sustainable Development Goals (SDGs): Challenges and Issues of the Preparedness Phase", hereafter referred as the " $15^{\text {th }}$ GAB Annual Seminar" or "the Seminar". It was held on the $6^{\text {th }}$ of May 2018 in Riyadh, Saudi Arabia It was an international forum where the GAB, the UN and INTOSAI worked together for supporting SAIs implementation internationally. Furthermore, this meeting ensured to successfully achieve the desired momentum by auditing the process at all levels. It also provided a platform for getting an in-depth understanding of the interrelated functions of the SAIs, INTOSAI, and UN. Several discussions related to the current themes as well as challenges were being organized; the main aim of which was highlighting the positive and negative aspects of SDG implementation at both national and international level.

The present research study intends to perform an in-depth evaluation of the institutions in order to understand their structural and professional mechanisms coupled with highlighting the challenging aspects which might hinder the performance efficacy to a great extent. Besides that, the research aims to analyze the phenomenon and hence propose all possible strategic frameworks which can bridge the identified gaps.

The research has been divided into different sections. It begins with an introduction which is followed by a well structure literary analysis. The third chapter has detailed methodological interventions which have been adopted to conduct the study. Finally, Synthesis of research symposia, discussions and research papers that were presented in the research conference have been included along with conclusion and recommendations.

\section{Background Review of the SDGs}

Before indulging in the evaluation of SDGs, their implementation and auditing, it is important to understand what SDGs are and the need for SDGs. In 2015, the UN and its member states, jointly established an ambitious and long-term plan, entailing broad issues by adopting the 2030 SDGs agenda. The UN declaration pledges that no one should be left behind and emphasizes that it is primary responsibilities of the member governments that they should assume primary responsibility to evaluate the national and regional performance targets and ensure that these plans should be implemented in their letter and spirit so that by the year 2030 SDGs can be achieved.

Brissett (2018) emphasized the importance of SDGs and argued that SDGs would contribute to bringing social change by elevating poor states and by universalizing the global economic system. The recognition of key economic and environmental problems of the less developed countries may eradicate these problems and reduce the power and wealth gap between the rich and the poor. Mawdsley (2018) calls attention towards the role of the private sector and suggested that in addition to public sector investor in SDGs, the need for private sector involvement and financing is also important. Such involvement would convert spending from 'billions to trillions' and would be beneficial for private sector enterprises. On the national level, when private sector enterprises involve themselves in SDGs, it would reduce the burden on the public sector and decrease reliance on non-state factors.

SDG implementation is a highly complex phenomenon entailing different challenging situations and aspects which are particularly related to professionalism, innovation, setting benchmarks and effective implementation of International Standards of Supreme Audit Institutions as being put forth by INTOSAI (2016). As an outcome, the Forum of INTOSAI Professional Pronouncements (FIPP) developed the overall process and further took 
many initiatives to process it. The technical experts of FIPP took responsibility for content development, consistency, and quality of IFPP. INTOSAI (2016) urged stakeholders that an on-going focus on improving professional pronouncements and standard-setting processes will ensure a high degree of capacity development along with ensuring an increased level of performance. For this, INTOSAI has to promote the use and implementation of ISSAIs.

The revision and the standard setting projects of INTOSAI are expected to end in 2019. INTOSAI (2017) conducted a symposium in Vienna and discussed opportunities and challenges of digitalization, open data, and data mining. Where development related to information and communication technologies are creating opportunities, the massive information generation is creating challenges for determining qualified audit-related information. This calls for increased involvement and role of SAIs for maintaining the quality of information through their audits.

After presenting an account of SDGs, the need for implementation and associated challenges, the next step in the process is to analyze auditing and associated challenges. Sachs \& Schmidt (2017) highlighted the importance of evaluating the level to which performance targets and the mechanism for analyzing such level. They suggested that the commitment of the member state governments to the SDGs necessitates the auditing of the communication of the SDGs guidance and the preparedness for implementation, and the sharing of learning experiences. This necessitates the national SAIs to play a key role in their respective jurisdiction and the involvement of INTOSAI as an international partner to the United Nations. Moreover, national SAIs can contribute by tracking progress and monitoring implementation for identifying improvement opportunities.

As part of the enhancement of auditing capacities, the two support bodies of INTOSAI, INTOSAI Development Initiative (IDI) and the Knowledge Sharing Committee (KSC), raise awareness by exchanging knowledge and experience, for supporting and encouraging SAIs in SDGs implementation. Such support comes in the form of intensive training courses, satellite and partnership programmes, training workshops and organizing related events. An example of this is INTOSAI's congress in Abu Dhabi. It identified four approaches through which INTOSAI and SAIs can participate in the achievement of the SDGs, namely, (1) evaluate member states' readiness (2) audit performance (3) participate in achievement and (4) prospects towards best practices $\left(22^{\text {nd }}\right.$ INCOSAI Report).

Research of Yonehara et al. (2017) argued that the achievement of SDGS relies mainly on practice-based monitoring and evaluation. Earlier, Bamberger et al. (2016) argued that instead of delaying it 2030, one should periodically review and audit the implementation process of goals and policies. Since the process of monitoring and evaluation in the first-phase is crucial as stakeholders are rushing towards the development and implementation of SDGs. Yonehara et al. (2017) re-conceptualizes the developmental matters of each phase and divided the SDGs program into three phases (table 1).

Table 1. Phases for SDGs evaluation

\begin{tabular}{|c|c|c|}
\hline Phase & Activities & Evaluation Concern \\
\hline Phase 1 (2016-2020) & Planning and initiation of major programs & -Proactive evaluation \\
\hline Phase 2 (2021-2025) & $\begin{array}{l}\text { Project continuation, } \\
\text { improvement, addition }\end{array}$ & $\begin{array}{l}\text {-Evaluability assessment } \\
\text {-Monitoring } \\
\text {-Formative evaluation }\end{array}$ \\
\hline Phase 3 (2026-2030) & $\begin{array}{l}\text { Project completion } \\
\text { Follow-up }\end{array}$ & $\begin{array}{l}\text {-Outcome evaluation } \\
\text {-Impact evaluation }\end{array}$ \\
\hline
\end{tabular}

Source: Yonehara et al. (2017)

Since the first phase has been concluded successfully, so one of the significant steps at this stage has been identified as performing an analysis of the preparedness level which will help in identifying the structural gaps and shortcomings while ensuring the development of coherent and well-versed programs in the future. Referring to work of Yonehara et al. (2017) and table 1, once SDG related programs, the analysis has identified a dire need of developing a stringent and robust monitoring system to evaluate the effectiveness, efficiency, and economy of the projects. This calls for the development and testing of monitoring and evaluation frameworks so that results can be substantiated.

Moreover, the situation also calls for the development of results and effect assessment related to target outcomes. Spangenberg (2017) argued that SDGs are diverse and have many inherent contradictions, so an impact monitoring and evaluation framework is needed. One has to look at the driving forces, pressures, states, impacts, and responses for looking at the challenges. In the case where the assessment fails to derive the desired outcomes, the next step would the evaluation of implementation aspects to identify any needed up gradations adhering to the situational requirements. 


\section{Methodology}

The research has been focused on understanding and evaluating the implication of SDG in coherence with the structured plan which was designed in 2015. The discussions and seminars continued in 2016 at INCOSAI (Abu Dhabi) and the 2017 UN / INTOSAI symposium. The core theme of $15^{\text {th }}$ GAB seminar was an evaluation of challenges and issues that SAIs had to tackle during the preparedness phase. This study aimed at updating the state of challenges faced in the preparedness phase and used secondary data obtained from previous conferences, seminars, congresses and symposiums on auditing of the implementation of SDGs particularly by INTOSAI and its affiliate organizations or partners.

The research has been conducted following a secondary data approach within the context of interpretivism paradigm. The existing discussions, panel arguments as well as presented points have been analyzed in order to perform an audit of the preparedness activities. As a direct participant in the seminar, the researcher had gained knowledge about all the staged of preparedness which helped in further evaluating and assessing the data set while contributing to authenticity, reliability, and validity of the subjected research. Additionally, the proceedings of the seminar were electronically recorded and were made available to the attendees on request. The researcher used the recorded proceedings and identified key themes and related discussion.

Following $22^{\text {nd }}$ INCOSAI Congress and the $24^{\text {th }}$ Symposium, in $2017,15^{\text {th }}$ GAB seminar was held in Saudi Arabia. The seminar aimed at extending the discussion on the audit and follow-up of SDGs through the provision of a platform for gathering senior officials and experts from an international and regional organization, local government and other concerned stakeholders who are involved in the implementation and audit of SDG. The core data for analysis was obtained from the discussions and talks delivered at $22^{\text {nd }}$ Abu Dhabi INCOSAI, the $24^{\text {th }}$ Vienna INTOSAI Symposium, and the $15^{\text {th }}$ Riyadh GAB Seminar. The secondary data, analysis and results or findings depend on the common ground as well as the divergence among the data sources. Moreover, it should be noted that the data are discussions, deliberations, recommendations or declarations that ensued from panel discussions and debates, and hence, the absence of presented papers might have a limitation of not being quoted or referenced.

Since the researcher had participated in the conference as an organizer, the opportunity to be included in all the activities and stages doubled the effectiveness of conducting this research along with increasing the reliability spectrum of the study. The opportunity to plan, convene, organize and follow the $15^{\text {th }} \mathrm{GAB}$ seminar added to the researcher's existing knowledge base. Acting in the senior role, the researcher had the opportunity of interacting with the key speakers and moderately related sessions.

Three key themes that were identified in the seminar were (1) evaluation of the current state of institutions and professional mechanisms for the implementation of SDGs, (2) analysis of challenges that may hinder effective implementation of such SDGs and (3) analysis of frameworks for solving the challenges and/or filling the gaps. The recorded proceedings of $15^{\text {th }} \mathrm{GAB}$ seminar were evaluated and findings were synthesized. It is important to highlight that synthesis was made on the experience of the key informants as well as key literature on the topic. The experiences evaluated were the ideas of the key informant (people knowledgeable about the research questions) who participate in the forums, panel discussions and debates. Moreover, findings are also based on a literature search (survey) since the researcher used existing for achieving research aim.

The nature of the data might arguably be criticized as being subjective. However, since those who presented or led the panel discussion and those who attended the seminars, conferences, congresses, or symposiums were very well informed and updated on the issue of the audit of the implementation of the SDGs, and during discussion, attendees had the opportunity to evaluate other's responses, ask question(s) and contradict, so it can be argued that data used in this research was unbiased.

\section{Analysis}

The Discussions are made at the 15th GAB Seminar include the challenges of non-uniformity of existing institutional structures and cultures for strategy development for auditing SDGs at the national level; and regional cooperative audit and the role of the supranational entities in SDG implementation. The conference covered different areas of SDGs including the current stage of auditing co-operative performance audit on preparedness in implementing the International Standards of Supreme Audit Institutions (ISSAI).

This research paper has integrated different themes that were covered in the 15th GAB Seminar. The main focus of this research paper is on the (1) evaluation of the current state of institutions and professional mechanisms for the implementation of SDGs, (2) analysis of challenges that may hinder effective implementation of such SDGs and (3) analysis of frameworks for solving the challenges and/or filling the gaps. In order to support readership, 
findings are linked with each of these themes.

\subsection{Evaluation of the Current State of Institutions and Professional Mechanism}

The first theme was the evaluation of the current state of institutions and professional mechanisms for the implementation of SDGs. Based on the synthesis of discussions held in $15^{\text {th }} \mathrm{GAB}$ seminar and analysis of literature, the researcher found that since its inception in 2015, the SDGs agenda of the UN and its implementation and auditing received due to support from all over the world.

UN and its member states are the owners of the Agenda, and the UN General Assembly takes up the responsibility of setting up regulatory and implementation frameworks. In 2012, the UN established the central or main platform of sustainable development at the UN level, called United Nations High-level Political Forum (HLPF), which later took the responsibility to monitor of the 2030 SDGs. It should be regarded as the first move of the UN towards supporting the SDG with institutional backing. This forum replaced the Commission for Sustainable Development of the UN. The format and organizational aspects of the forum are outlined in the UN Resolution 67/290 of 2013. The High-level Political Forum provides the full and active participation of the UN member states and its specialized agencies, and it adopts intergovernmental negotiated political declarations.

Under the auspices of the UN General Assembly, Economic and Social Council of the UN will organize the annual meetings of the HLPF. Moreover, the United Nations Department of Economic and Social Affairs (UNDESA) and its divisions have been and will work on the common goal of SDGs and collaborate with its regional and country level partner. This will strengthen cooperation among stakeholders. Moreover, as per UN Resolution 70/299 of 2016, UNDESA assumes the responsibility of reviewing and following up implementation and progress of SDGs during 2017-2019. Division for Sustainable Development Goals (a Division of the UNDESA) acts as the Secretariat for the HLPF. It provides support in capacity building for the attainment of 17 SDGs and their related thematic issues (Division for Sustainable Development Goals, 2017).

United Nations Development Programme (UNDP), another UN body, advocates the UN's international development network and support in improving and connecting member states (Turner, 2008). UNDP supports the implementation of SDGs by fostering sustainable development, democratic governance and peacebuilding, and climate and disaster resilience. It works with the United Nations Development Group (UNDG) for the eradication of poverty.

Besides its role as a partner for development work and manager of the Resident Coordinator system, UNDP assists in reinforcing joint efforts on development in forums like Economic and Social Council and the General Assembly of the UN. Shah (2018), Deputy Assistant Administrator and Chief Finance Officer of the UNDP and a speaker at the 15th GAB Seminar states that the UNDP:

(1) Tailor challenges and commitments at country level needs,

(2) Bring knowledge achieved from across the world,

(3) Provide access to UNDP tools vital

(4) Provide integrated solutions to complex problems

(5) Support the UN development system at the country level.

(6) Identify means (tools, finance, and technology) for implementing the 2030 Agenda

(7) De-risk projects, and

(8) Help countries in broadening the pool of partners.

Finally, in order to put in place a strong follow-up and auditing mechanism for the implementation of the SDG, the UN adopted a robust framework of key performance measures. It provides statistical information to review progress, inform policy, and ensure accountability of all stakeholders.

Steiner (2018) from INTOSAI General Secretariat and one of the speakers at the $15^{\text {th }}$ GAB Seminar, highlighted that the UN in its resolutions 66/209 of 2011 and 69/228 of 2014 recognized the need that SAIs should be independent and promote transparency, efficiency and responsibility of public management in achieving SDGs. Resolution 66/209 of 2011 of the UN General Assembly, titled "Promoting the efficiency, accountability, effectiveness, and transparency of public administration by strengthening supreme audit institutions," promotes that the SAIs must be independent. It is "the crowning conclusion of the common efforts of all SAIs to strengthen their independence and for recognition of the Lima and Mexico Declarations." (UN Resolution A66/209).

This resolution supports the independence of SAIs from their respective governments or audited bodies and 
mandates them to perform their professional duty. Secondly, in Resolution 69 / 228 of 2014 titled "Promoting and fostering the efficiency, accountability, effectiveness, and transparency of public administration by strengthening supreme audit institutions", the UN General Assembly recognizes that SAIs can achieve their duties impartially and effectively only if they are independent and are saved against any pressures. It also recognizes the significant role of SAIs in promoting many important governance concepts (e.g., efficiency, accountability, effectiveness, and transparency) related to administration of public institutions, which assist in accomplishing the planned national and international development targets and priorities (Resolution 69 / 228 of 2014).

It is indicative that the two UN General Assembly resolutions establish the basis for institutional and professional backing and the endorsement of the SAIs of the Member States and their global organization, the international organization of SAIs, the INTOSAI. Thirdly, in 2015 , the $23^{\text {rd }}$ UN/INTOSAI Symposium reaffirmed the position of the SAIs concerning sustainable development as the core theme of the UN Post-2015 Development Agenda (the $23^{\text {rd }}$ UN/INTOSAI Symposium Report).

It is suggested that the role of INTOSAI in the auditing process of SDGs has also indirectly been affirmed on the Symposium, and the INTOSAI included the SDGs as the important theme of its Strategic Plan for 2017-2022. The Report recommendation states: "The United Nations expects INTOSAI and the national SAIs to develop the necessary standards and capacity to be able to contribute to the implementation and the achievement of the Sustainable Development Goals, for example via national oversight and control mechanisms".

The main function of IDI is the provision of capacity building training to regional and national audit bodies. It also supports the Knowledge Sharing Committee (KSC) for fostering knowledge sharing, transferring experience, and skills among the SAIs. Fifthly, the INTOSAI Congress (INCOSAI) of 2016 held in Abu Dhabi stressed on the professionalism of auditing and innovation in standard setting that is aimed at revising and implementing the ISSAI framework. As a result Forum of INTOSAI Professional Pronouncements (FIPP) was developed for revising the due process for INTOSAI's Framework of Professional Pronouncements.

Monroe-Ellis (2018), in her speech on the GAB Seminar highlighted the case of Jamaica that has been at the forefront of the SDG program. She highlighted that Jamaica had developed its development plan in 2009 coincidently naming it Vision 2030. It is highly with United Nations SDGs. Regarding Jamaican government planning of SDGs implementation, Mrs. Pamela Monroe-Ellis noted that (1) the government is currently developing a roadmap for SDGs implementation thus outlining the critical steps to achieve the 2030 agenda, and (2) involving a number of key government Agencies, namely the Planning Institute of Jamaica, the Ministry of Foreign Affairs, and the Statistical Institute of Jamaica, to collaborate in the planning and implementation process.

The Report also affirmed INTOSAI's role of "ensuring standard-setting, knowledge-sharing, capacity development goals and other initiatives that are coordinated effectively in order to support the professional capacity of SAIs, including the ability to audit national development goals and the related SDGs" (23 ${ }^{\text {rd }}$ UN/INTOSAI Symposium Report). This is another indicator that the INTOSAI and the UN have put in place the professional preparedness for the implementation of the SDGs. Fourthly, as part of setting the professional preparedness, INTOSAI developed a support body, INTOSAI Development Initiative (IDI).

Additionally, the SAI of Jamaica has been active in its contribution and support government endeavors. It held meetings with the Jamaican Statistical Institute to determine the process to identify relevant stakeholders. This was in line with the holistic approach to planning the SDGs implementation. Moreover, SAI Jamaica gathered quite a bit of information during its audits and provided meaningful information to the Statistical Institute keeping its status of remaining independent and objective.

\subsection{Evaluation of Challenges Hindering Implementation}

The second theme of GAB was the analysis of challenges that may hinder effective implementation of such SDGs. Based on the synthesis of discussions held in $15^{\text {th }} \mathrm{GAB}$ seminar and analysis of literature, the researcher found that even though the actions taken by the UN show that there is global institutional preparedness for implementation of SDGs, the $15^{\text {th }}$ GAB Seminar showed that there were some vital requirements to be considered for facilitating the institutional preparedness.

(1) Consideration at the UN level: According to the $15^{\text {th }} \mathrm{GAB}$ Seminar, the speaker from the United Nations Office of Internal Oversight (UNOIOS). Mendoza (2018) suggested that there were still some risks for developing the auditing of SDGs that were identified by the UN General Assembly. These risks were:

a) The agenda was not matched by the significant increase in resources needed; 
b) UN SDGs may not have established a policy to support the needs assessment of member states in identifying resource gaps;

c) Secretariat programmes may not have the strategic funding policy to advocate for the agenda 2030 and for supporting member states with capacity building programmes;

d) The Secretariat may not have a holistic strategy at the international, regional and global levels to support high-level political reform in enabling member states with the means of implementation; and

e) Programmes may not have mechanisms to coordinate the implementation of SDGs in programmes of work.

(2) Planning approach consideration at the national level: Mr. Darshak Shah (2018) highlighted that SDGs implementation requires a holistic approach and cooperation among stakeholders. He argued that governments planning systems were not yet fully geared to include all groups of stakeholders in the planning phase and suggested more specifics on planning approach.

Mihm (2018), the Managing Director of Strategic Issues, US Government Accountability Office reminded on GAB Seminar that the whole government approach of planning should (a) focus on the expected performance in a cross-cutting way that look across individual programmes and ministries (b) consider vertical integration of programmes at National level down to a more localized implementation level (c) require government to be focused on innovation for systematically finding new, different, and more creative ways to achieve results.

(3) Diversity in planning approach: It is reflected that there is no uniformity of government planning systems that would be fully geared to include all groups (stakeholders and sectors) in the planning phase. Regarding this, Mr. Darshak Shah (2018) noted that some countries still need to ensure the adequacy of institutional architecture and platform, suggesting that the non-uniformity in the planning system would risk the achievement of the motto of the SDG Agenda "No None is Left Behind" and the issue should be addressed at the global, regional, and national levels. He also suggested that SDGs can be implemented if the government adopts a holistic planning approach by involving all categories of stakeholders.

(4) Diversity in risks: It was indicated in the $15^{\text {th }} \mathrm{GAB}$ Seminar that there were risks of the diversity of countries that may influence the uniformity of implementation of the SDGs. Mr. Darshak Shah (2018), argued that countries face different types of risks including geographical, political and societal risks. He highlighted the need for engagement of multiple sectors of society along with difficulty in tracking, monitoring and quantifying results and success.

(5) Diversity in quality and comparability among the Member States: It is evident that there is a difference in culture and institutional infrastructure among the member states. This might influence diversity in quality and comparability of SDGs implementation and the audit approach and activity. Mrs. Heidi Mendoza (2018) stated that Secretariat programmes might not have prepared statistical programmes with the necessary capacity to support member states to improve gaps in quality and comparability. This necessitated the preparation of statistical programmes that would enable the improvement of quality and comparability for detecting gaps and enhancing catch-ups for harmonization.

Even though stakeholders are making necessary efforts for implementing the auditing of the SDGs, it is still questionable whether there is uniformity at national level SAIs. There are some serious problems or challenges stated by the speakers on the $15^{\text {th }}$ GAB Seminar. The challenging issues that the UN, the Member States of the UN, INTOSAI, and SAIs need to address and solve the followings.

(1) The absence of data at the national level to national audit bodies: As Mrs. Heidi Mendoza (2018), the under-secretary for the United Nations Office of International Oversight (OIOS) stated on $15^{\text {th }}$ GAB Seminar, this problem was the obstacle to ensure policy implementation at national, regional and global levels.

(2) Lack of independence of SAIs: According to Mrs. Pamela Monroe-Ellis (2018), Auditor General of Jamaica and the speaker at the $15^{\text {th }}$ GAB Seminar, the lack of independence was related to the governance system in place. She stated that this problem could render SAIs unable to respond promptly to evolving dynamics thus running the risk of being unable to maintain relevance besides impairing the objectivity and effectiveness of SAIs. Dr. Silke Steiner (2018) from INTOSAI General Secretariat, and a speaker at the GAB Seminar, suggested that the obstacles to SAIs as reviewed by IDI report of 2017 made by the SAI Global reveals that SAIs were hampered in the general performance by constraints in their operational, legal, and financial independence. Noting this is worrying, she suggested that only Independent and capable SAIs can 
effectively contribute to the successful implementation of SDGs and that household limited financial Independence and limited rights with regards to the publication of audit reports had a negative impact on the capacity of SAIs. This indicated the requirement of making SAIs independent regarding operational, legal and financial perspectives.

(3) Diversity in the involvement of SAIs in requests for support in implementing SDGs: It is raised in the GAB Seminar that there is non-uniformity in the involvement of SAIs in orientations and pieces of training in the national and international plans and the focus was mostly the consideration of the mainstreaming the SDGs in the plans. This was taking out the important body, the SAIs, out of the equation in which they have a vital role in auditing implementation of the SDGs. Mr. Darshak Shah (2018) noted that Saudi Arabia, to the contrary, was continuing to make good progress in considering SAIs for orientations and training.

(4) The trade-off between complexity and quality in SAIs work: On the Seminar, Mr. Khalid Hamid (2018), Chairman of INTOSAI Financial Auditing, Accounting Subcommittee, and the Supervisory Committee on Emerging Issues, and a speaker at GAB Seminar suggested that the relevance of SAIs rests on two dimensions of complexity and quality. This might be suggested that as the complexity of the SAIs work enhances, the quality of the work may decrease. Linking to ISSAI 12, which defines the operational principles of SAIs in accordance to the fundamental expectation of making a difference to the lives of citizens, he notes that the real value adding of SAIs is related to public interest and hence the whole public assurance process. This suggested the requirement of hard work of SAIs to take upon their responsibility to the public interest to counter the trade-off between complexity and quality. Related to non-uniformity of complexity dimension of SAIs work, he suggested that the concept of scalability poses difference of doing full-scale work and focused work and that in small countries no need to do full ISSAI audits and hence they can do risk-based limited amounts as in large countries.

(5) Approach to auditing: The traditional approach to auditing financing and compliance audit. Mr. Christopher Mihm (2018), the Managing Director of Strategic Issues, US Government Accountability Office, speaking on GAB Seminar highlighted that a holistic approach to auditing had to be evolved. $\mathrm{He}$ suggested that the traditional financing and compliance audit would remain bedrock to what we do in the value and benefits they will provide to our citizens. He suggested that in the governance complexity being witnessed and the new tools and mechanisms that governments are using to implement the SDGs; such tools, the mechanisms, and the methodologies for audit should evolve with the complex arrangements of governance process and structure the government uses and the activities that are being used to implement the SDGs and finally the resulting outcomes or achievements.

He added that auditing must evolve to the holistic approach to auditing, in which the traditional approaches of financing and compliance audit will remain the bedrock and that the tools, the mechanisms and the methodologies for audit should evolve to cop up with the new tools and mechanisms the governments are using to implement the SDGs that arose with complexity of governance and ensuring arrangements. Auditing should look at the outcomes or achievements of the governance processes and structures and activities used to implement SDGs.

(6) Approach to audit plan: The recommended approach to the audit plan of the SDGs raised on GAB Seminar is the thematic approach to audit plan that needs to be developed. Mrs. Pamela Monroe-Ellis (2018), Auditor General of Jamaica, states that they used five themes - project plan, resource management, technology, governance, and procurement - in audit plan intended to assess the effectiveness of the government plan to implement the 17 SDGs and to review the economic performance of key ministries such as Ministry of Finance to ensure fiscal prudence and responsibility. Our plan also spans issues of a social and economic nature.

(7) Approach to reporting: It is noted on the GAB Seminar that the whole concept of integrated reporting is moving away from the purely financial reporting that most governments and even the UN system are used to. Regarding SAIs reporting, Mr. Darshak Shah (2018) noted the need to move in the direction of integrated reporting (from financial reporting) and then the SAIs have to start to audit the process of integrated reporting. The auditing and evaluation must always be aligned with national capacities.

Highlighting the case of Jamaica, Mrs. Pamela Monroe-Ellis (2018) highlighted the priority given by SAI Jamaica to the preparation of the Strategic Plan of its own as a development plan. The plan links its strategies with the 12 principles in ISSAI 12 such that SAI Jamaica remains relevant through the delivery of high-quality reports with actionable recommendations to meet stakeholder needs. To be able to cop up with this task, SAI Jamaica needed to build capacity by taking steps to rank audit candidates based on the impact on the outcome of 
its development plan.

Additionally, SAI Jamaica has developed the thematic audit plan 2017-2019 to audit the effectiveness of the government plans to implement the 17 SDGs. This audit plan reflects five fundamental themes, namely (1) project planning, (2) resource management, (3) technology, (4) governance, and (5) procurement. This framework would enable SAI Jamaica to assess and audit the government plans and its implementation progress and to ensure whether everything is on the right track.

Moreover, SAI Jamaica is required to consider the economic side and hence to review the economic performance of the Jamaican Ministry of Finance in keeping track with the legislated fiscal targets. This is a critical element of the mechanism to safeguard and engender fiscal prudence and responsibility. These steps of SAI Jamaica indicated that it is worthwhile to take a proactive role in professional auditing rather than taking a reactive position. Furthermore, recognizing that it must be engaged in multifaceted audit approach to achieve better audit outcomes, SAI Jamaica pursued a stakeholder engagement enhancement process. To this effect, through the initiative led by IDI, SAI Jamaica has recently completed and published the stakeholder engagement.

Mrs. Pamela Monroe-Ellis highlighted that this approach (1) could be used to identifying and directing limited resources to areas of greatest need, (2) would play an essential role in scrutiny and advocacy, and (3) would develop the understanding of stakeholders and further the mandate of the SAI Jamaica by amplifying its role. Hence, SAI Jamaica has had many discourses with civil society representatives. Regarding the technical expertise of human resources for auditing, Mrs. Pamela Monroe-Ellis informs that SAI Jamaica included economists along with experts from other areas. This suggests that it is not only accountants' expertise is enough to implement the auditing of the complex SDG implementations and that accountants, statisticians, and others are required.

In order to make sure of preparedness for the expected assessment and evaluation in the auditing process, SAI Jamaica worked closely with the Jamaican Statistical Institute. It held meetings to determine the process of identifying relevant stakeholders and providing meaningful information to the Statistical Institute. Hence, SAI Jamaica gathered information during their audits and hence could assist in contributing to the completion of the $39 \%$ of 223 relevant indicators that the Institute could not have produced yet.

Finally, on the regional INTOSAI, Caribbean Organization of Supreme Audit Institutions (CAROSAI), Mrs. Pamela Monroe-Ellis (2018) highlighted three priority areas in support of this outcome at CAROSAI level, namely, (1) attainment of high quality audits creating regional impact through collaborative and parallel audits, (2) use of strategic performance measurement and reporting tools for effectiveness and capacity building and professionalization of SAIs, and (3) use of active stakeholder engagement techniques to maintain relevance by building trust and confidence among stakeholders so as to have greater audit impact.

\subsection{Solutions for Solving Challenges and Filling Gaps}

The third theme was the analysis of frameworks for solving the challenges and/or filling the gaps. Following the presentations of the speakers and the discussions of the participants of the $15^{\text {th }}$ GAB Seminar, different complementing remarks of importance were noted that could serve as recommendations on the issues and challenges that were mentioned earlier in this paper. It was observed that due to the complexity of the 2030 Agenda, and the overlapping nature of governance complexity of the programmes and outcomes, and noting that the government (its ministries and agencies) must work together using a holistic approach or whole government approach, Mr. Mihm and others suggest the following recommendations:

(1) There is a need to be able to focus on performance across the governance bodies, where there must be a horizontal integration across various ministries, and vertical integration at the national level that involves civil society and stakeholders' engagement so that it creates the whole government approach.

(2) The governments need to be focused on innovation, which is required by the whole government perspectives. They should systematically look for new, different, and more creative ways in order to achieve results. This calls for investment in technology.

(3) The governments need to be using data and evidence to drive decisions, and the plenty of evidence gaps discussed in the Seminar should be filled and identify what works.

(4) Governments need to manage systematic risk across the entire enterprise across a delivery network of organizations or activities rather than the risk of any individual organization or activity in order to identify the riskiest partner not only from government bodies but also from a contractor or the civil society organization. 
(5) Governments need to adopt appropriate collaborative mechanisms and network management by putting in place appropriate institutional arrangements as part of the silo-busting approach.

(6) Governments need to build organizational capacity at the center of government in order to enhance new and different ways of doing business in order to leverage the capacity of doing outside the center. This requires building capabilities in the strategic management that requires capabilities in in-depth data analysis and all others.

(7) Governments must employ strategies for public engagement openness and transparency such that they are told the critics or views heard from society.

(8) Audits must evolve, and the concept referred to as a holistic approach of auditing in addition to the traditional approaches to financial compliance. It is needed to make sure that the tools, the mechanisms, and the methodologies put in place for audit evolve in tandem with the complexity of the arrangements used by governments to implement the 2030 Agenda.

\section{Conclusion}

This research paper recalled the core of the $15^{\text {th }} \mathrm{GAB}$ Seminar by evaluating and synthesizing key themes related to the implementation of the SDGs both on the national and the international level. The analysis made has shown that the presentations and discussions at the $15^{\text {th }} \mathrm{GAB}$ Seminar indicated there is institutional preparedness for implementing the SDGs and that there is professional preparedness for auditing the implementation of the SDGs.

The exploratory analysis of the global institutional preparedness indicates that (1) the necessary institutional frameworks for coordinating, following-up, and reviewing have been established at the UN level, and (2) UNDP has been functioning at global and country levels and harmonizing the diversity of cultures, which is one of the themes of the 15th GAB Seminar. UNDP is serving the role of advisory, coordination and integrating roles and offering the services noted above. Additionally, the analysis of the requirements for institutional preparedness from the $15^{\text {th }}$ GAB Seminar presentations and discussions on diversities related to institutional preparedness suggests that there are specific areas of priority for achieving harmonization among the Member States due to the existing cultural diversity among them. This is very important for ensuring the motto of the UN on SDG Agenda, namely, "No One is Left Behind."

Moreover, there is an indication from the analysis that the necessary professional preparedness for implementing the SDGs has been put in place at the global and national levels. Even though there is the necessary preparedness for implementing the auditing of the SDGs, it is still questionable whether there is uniformity at national level SAIs. There are some serious problems or challenges stated by the speakers on the $15^{\text {th }}$ GAB Seminar. The challenging issues that the UN, the Member States of the UN, INTOSAI, and SAIs need to address and solve are specified on the Seminar. Based on the synthesis of GAB, future researchers and conferences should corroborate the points raised in the paper to evaluate their relevance and implementation in other contexts (for example, countries, SAIs, etc.).

\section{References}

Bernstein, S. (2013). The role and place of the High-level Political Forum in strengthening the global institutional framework for sustainable development. Munk School of Global Affairs, University of Toronto.

Biermann, F., Kanie, N., \& Kim, R. E. (2017). Global governance by goal-setting: the novel approach of the UN Sustainable Development Goals. Current Opinion in Environmental Sustainability, 26, $26-31$. https://doi.org/10.1016/j.cosust.2017.01.010

Brissett, N. O. (2018). Sustainable Development Goals (SDGs) and the Caribbean: Unrealizable promises? Progress in Development Studies, 18(1), 18-35. https://doi.org/10.1177/1464993417734440

Clayton, T., \& Radcliffe, N. (2015). Sustainability: a systems approach. Routledge.

Crane, A., \& Matten, D. (2016). Business ethics: Managing corporate citizenship and sustainability in the age of globalization. Oxford University Press.

Division for Sustainable Development Goals (2017, January 18). Capacity Development, Including Supporting National Voluntary Reviews. Retrieved from: https://sustainabledevelopment.un.org/about/dsd

Guthrie, J., Ball, A., \& Farneti, F. (2010). Advancing sustainable management of public and not for profit organizations.

Hak, T., Janoušková, S., \& Moldan, B. (2016). Sustainable Development Goals: A need for relevant 
indicators. Ecological Indicators, 60, 565-573. https://doi.org/10.1016/j.ecolind.2015.08.003

Hamid, K. (2018, September). The relevance of SAIs on Complexity and Quality. Paper presented at the GAB: The $15^{\text {th }}$ GAB Seminar, Riyadh, Kingdom of Saudi Arabia.

Holden, E., Linnerud, K., Banister, D., Schwanitz, V. J., \& Wierling, A. (2017). The Imperatives of Sustainable Development: Needs, Justice, Limits. Routledge. https://doi.org/10.4324/9780203022177

INTOSAI (2019, January 27). International Organization of Supreme Audit Institutions - Strategic Plan of INTOSAI 2017-2022. INTOSAI. Retrieved from: http://www.intosai.org/about-us.html

INTOSAI (2017, January 18). International Organization of Supreme Audit Institutions - Strategic Plan of INTOSAI 2017-2022. INTOSAI. Retrieved from:

http://www.intosai.org/news/previous-information/previous-information-2017/271017-innovations-intosai-s tandard-setting-structure.html

INTOSAI (2016, January 18). 24 $4^{\text {th }}$ UN/INTOSAI Symposia. Retrieved from: http://www.intosai.org/events/gallery/2017/24th-unintosai-symposium.html

Laszlo, C., \& Zhexembayeva, N. (2017). Embedded sustainability. In Embedded Sustainability (pp. 116-140). Routledge. https://doi.org/10.4324/9781351278324-7

Mawdsley, E. (2018). From billions to trillions' Financing the SDGs in a world 'beyond aid. Dialogues in Human Geography, 8(2), 191-195. https://doi.org/10.1177/2043820618780789

Mendoza, H. (2018, May). Risks for Developing the Auditing of SDGs. Paper presented at the GAB: The $15^{\text {th }}$ GAB Seminar, Riyadh, Kingdom of Saudi Arabia.

Mihm, C. (2018, May). Government Approach to Planning. Paper presented at the GAB: The $15^{\text {th }}$ GAB Seminar, Riyadh, Kingdom of Saudi Arabia.

Monroe-Ellis, Pamela (2018, May). The progress of Member States - Jamaican Institutional Preparedness: The $15^{\text {th }}$ GAB Seminar, Riyadh, Kingdom of Saudi Arabia.

Reichborn-Kjennerud, K., \& Johnsen, A. (2018). Performance audits and supreme audit institutions' impact on public administration: The case of the office of the auditor general in Norway. Administration \& Society, 50(10), 1422-1446. https://doi.org/10.1177/0095399715623315

Sachs, J. D., \& Schmidt-Traub, G. (2017). Global fund lessons for sustainable development goals. Science, 356(6333), 32-33. https://doi.org/10.1126/science.aai9380

Shah, D. (2018, September). Role of UNDP in SDG Implementation. Paper presented at the GAB: The $15^{\text {th }}$ GAB Seminar, Riyadh, Kingdom of Saudi Arabia.

Spangenberg, J. H. (2017). Hot air or comprehensive progress? A critical assessment of the SDGs. Sustainable Development, 25(4), 311-321. https://doi.org/10.1002/sd.1657

Steiner, S. (2018, May). Role of SAIs in SDG Implementation. Paper presented at the GAB: The $15^{\text {th }}$ GAB Seminar, Riyadh, Kingdom of Saudi Arabia.

$22^{\text {nd }}$ INCOSAI: Abu Dhabi Declaration: http://www.intosai.org/fileadmin/downloads/downloads/0_news/2016/141216_EN_AbuDhabiDeclaration.p df.pdf; Accessed 11 September 2018

https://undg.org/; Accessed 10 September 2018

$23^{\text {rd }}$ UN/INTOSAI Symposium Report: http://www.intosai.org/fileadmin/downloads/downloads/5_events/symposia/reports/EN_23_UN_INT_Symp Report_Final.pdf; Accessed 13 September 2018

$24^{\text {th }}$ INTOSAI Symposium: https://publicadministration.un.org/en/news-and-events/calendar/moduleid/1146/ItemID/2943/mctl/EventDe tails; Accessed 13 September 2018

http://workspace.unpan.org/sites/Internet/Documents/UNPAN97270.pdf; Accessed 13 September 2018

INTOSAI: http://www.intosai.org/about-us.html Accessed 14 August 2018.

INTOSAI Development Initiative (IDI):

http://www.intosai.org/en/about-us/intosai-development-initiative-idi.html Accessed 01 September 2018.

INTOSAI KSC: http://www.intosaiksc.org/default.php?syn=1\&e=0 Accessed 01 September 2018. 
http://www.intosai.org/committeesworking-groupstask-forces/goal-3/ksc.html Accessed 2 October 2018

INTOSAI Strategic Plan:

http://www.intosai.org/fileadmin/downloads/downloads/1_about_us/strategic_plan/EN_INTOSAI_Strategic _Plan_2017_22.pdf; Accessed 15 September 2018

GAB: The $15^{\text {th }}$ GAB Seminar: http://www.gab.gov.sa/en/semenar/seminar15/Pages/smn_title.aspx, Accessed 29 August 2018.

Lima Declaration - Auditing: http://www1.worldbank.org/publicsector/pe/befa05/LimaDeclaration.pdf; Accessed 12 September 2018

Mexico Declaration on SAI: https://www.nku.gov.sk/documents/10272/98330/Mexico+Declaration.pdf; Accessed 12 September 2018

SDGs: SAIs and Regions: http://www.intosai.org/about-us/sdgs-sais-and-regions.html Accessed 01 September 2018.

Thawani (2018). Achieving the Sustainable Development Goals (SDGs) with Lesser Cost by Adopting Quality Management Strategies, ISSN 2409-5532. International Journal of Civil Service Reform and practice, 3(1), Taiwan

The 2030 Agenda for Sustainable Development: https://sustainabledevelopment.un.org/content/documents/21252030\%20Agenda\%20for\%20Sustainable $\% 2$ 0Development\%20web.pdf Accessed 15 September 2018

Turner B. (2008) United Nations System. In: Turner B. (eds) The Statesman's Yearbook. The Statesman's Yearbook. Palgrave Macmillan, London.

Yonehara, A., Saito, O., Hayashi, K., Nagao, M., Yanagisawa, R., and Matsuyama, K. (2017). The role of evaluation in achieving the SDGs. Sustain. Sci. 12, 969-973. https://doi.org/10.1007/s11625-017-0479-4

UN DESA: https://www.un.org/development/desa/en/ Accessed 10 September 2018

UN Resolution A66/209: http://www.intosai.org/fileadmin/downloads/downloads/0_news/2012/UN_Resolution_A_66_209_E.pdf; Accessed 13 September 2018

UN Resolution A66/209: http://www.intosai.org/ru/novosti/bolee-rannjaja-informacija/2011/010112-un-resolution-a66209.html Accessed 10/09/ 2018

UN Resolution 67/290: http://www.un.org/ga/search/view_doc.asp?symbol=A/RES/67/290\&Lang=E; Accessed 13 September 2018

UN Resolution A69/228 Accessed from: http://www.intosai.org/fileadmin/downloads/downloads/0_news/2014/EN_Resolution_69_228.pdf Accessed 10/09/ 2018

UN Resolution 71/313: http://ggim.un.org/documents/A_RES_71_313.pdf; Accessed 15 September 2018

UN Resolution 69 / 228: http://www.intosai.org/fileadmin/downloads/downloads/4_documents/publications/eng_publications/EN_R esolution_69_228.pdf; Accessed 15 September 2018

UN Resolution 70/299: http://undocs.org/a/res/70/299; Accessed 15 September 2018

United Nations Development Group: https://undg.org/; Accessed 10 September 2018

\section{Copyrights}

Copyright for this article is retained by the author(s), with first publication rights granted to the journal.

This is an open-access article distributed under the terms and conditions of the Creative Commons Attribution license (http://creativecommons.org/licenses/by/4.0/). 